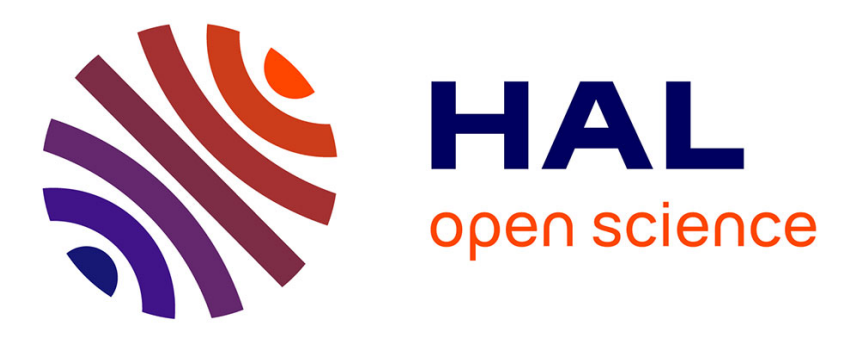

\title{
Positron Studies of Oxide-Semiconductor Structures
}

\author{
A. Uedono, Lumei Wei, T. Kawano, S. Tanigawa, R. Suzuki, H. Ohgaki, T. \\ Mikado
}

\section{To cite this version:}

A. Uedono, Lumei Wei, T. Kawano, S. Tanigawa, R. Suzuki, et al.. Positron Studies of OxideSemiconductor Structures. Journal de Physique IV Proceedings, 1995, 05 (C1), pp.C1-49-C1-56. 10.1051/jp4:1995105 . jpa-00253541

\section{HAL Id: jpa-00253541 https://hal.science/jpa-00253541}

Submitted on 1 Jan 1995

HAL is a multi-disciplinary open access archive for the deposit and dissemination of scientific research documents, whether they are published or not. The documents may come from teaching and research institutions in France or abroad, or from public or private research centers.
L'archive ouverte pluridisciplinaire HAL, est destinée au dépôt et à la diffusion de documents scientifiques de niveau recherche, publiés ou non, émanant des établissements d'enseignement et de recherche français ou étrangers, des laboratoires publics ou privés. 


\title{
Positron Studies of Oxide-Semiconductor Structures
}

\author{
A. Uedono, L. Wei, T. Kawano*, S. Tanigawa, R. Suzuki**, H. Ohgaki** and T. Mikado** \\ Institute of Materials Science, University of Tsukuba, Tsukuba, Ibaraki 305, Japan \\ * Radioisotope Center, University of Tsukuba, Ibaraki 305, Japan \\ ** Electrotechnical Laboratory, 1-1-4 Umezono, Tsukuba, Ibaraki 305, Japan
}

The annihilation characteristics of positrons in $\mathrm{SiO}_{2}$ films grown on Si substrates were studied by using monoenergetic positron beams. Doppler broadening profiles of the annihilation radiation and lifetime spectra of positrons were measured as a function of incident positron energy for $\mathrm{SiO}_{2} / \mathrm{Si}$ structures fabricated by various oxidation techniques. From the measurements, it was found that the formation probability of positronium (Ps) atoms in $\mathrm{SiO}_{2}$ films strongly depends on the growth condition of $\mathrm{SiO}_{2}$ films. The present investigation shows that positrons provide a sensitive and nondestructive probe for the characterization of $\mathrm{SiO}_{2}$ films grown on Si substrates.

\section{INTRODUCTION}

Oxide films used in LSI devices must exhibit good electrical characteristics and provide long-term reliability. Various charges and traps, however, are formed in $\mathrm{SiO}_{2}$ films [1]. These defects affect ideal operations of LSI devices. The trapping sites of the carriers seem to be related to structures of $\mathrm{SiO}_{2}$ films and of $\mathrm{SiO}_{2} / \mathrm{Si}$ interfaces. Analyzing techniques such as electron spin resonance, $\mathrm{X}$ ray photoelectron spectroscopy and electrical measurements are not adequate for full understanding of characteristics of $\mathrm{SiO}_{2} / \mathrm{Si}$ intertaces and the atomic structure of $\mathrm{SiO}_{2}$ films. With the development of high current monoenergetic positron beams, it is now possible to profile defects, multilayers and interfaces in the subsurtace region [2]. The advantage of this technique is that the implantation profile of positrons can be adjusted to a restricted region of interest in the specimen by accelerating positrons to the desired energy. This technique has been successfully used to characterize $\mathrm{SiO}_{2}$ films grown on $\mathrm{Si}$ substrates and $\mathrm{SiO}_{2} / \mathrm{Si}$ interfaces [3-16]. In the present paper, we summarize studies of the annihilation characteristics of positrons in $\mathrm{SiO}_{2}$ films grown on $\mathrm{Si}$ substrates by different oxidation techniques.

When positrons are implanted into condensed matter, they rapidly slow down to thermal energy. After this thermalization process, a positron annihilates with an electron from the surrounding medium into two $511 \mathrm{keV} \gamma$ quanta. The motion of a positron-electron pair causes a Doppler shift in the energy of the annihilation photons. In a solid containing defects, a freely diffusing positron can be localized in vacincy-type defects by a Coulomb repuision from ion cores. Since the momentum distribution of electrons in such defects is different from that in the bulk. one can detect defects by measurements of Doppler broadening protiles of the annihilation radiation. The change in the Doppler broadening spectrum is characterized by the lineshape parameter $S$. which is the ratio of counts in the central region of the spectrum to the total count [2]. When positrons are trapped by vacancy-type defects, the !ifetime of positrons increases because of a reduced electron density in such defects. Thus, one can also detect vacancy-type defects by measurements of lifetime spectra of positrons.

A positronium ( $\mathrm{Ps}$ ) atom, a hydrogen-like bound state between a positron and an electron, is known to form in a vitreous quartz ( $\left.\mathrm{v}-\mathrm{SiO}_{2}\right)$ [17]. Ps exhibits two spin states which are called para-Ps, p-Ps, and ortho-Ps, o-Ps, for the singlet state and the triplet state, respectively [18]. A ratio of the formation probability of o-Ps to that of $\mathrm{p}-\mathrm{Ps}$ is 3 in vacuum due to spin statistics. The intrinsic lifetime of p-Ps is 
$\sim 125 \mathrm{ps}$ and that of o-Ps is $\sim 140 \mathrm{~ns}$. In condensed matter, however, the lifetime of o-Ps is only $1 \sim 3 \mathrm{~ns}$ because the positron involved in o-Ps can annihilate with one of the surrounding electrons rather than its own partner. This process is called the "pick-off" annihilation of o-Ps.

\section{EXPERIMENT}

The specimens used in the present experiment were Czochralski-grown Si wafers with a (100) orientation (p-type, $10 \Omega \mathrm{cm}$ ). The oxide films with a thickness of $166 \mathrm{~nm}$ were grown on the Si substrates in $\mathrm{O}_{2} / \mathrm{H}_{2}$ gas at $650{ }^{\circ} \mathrm{C}$ and at $1000^{\circ} \mathrm{C}$, respectively. In order to know the annihilation characteristics of positrons at the $\mathrm{SiO}_{2} / \mathrm{Si}$ interface, positrons implanted into the $\mathrm{SiO}_{2}$ film were accumulated at the $\mathrm{SiO}_{2} / \mathrm{Si}$ interface by applying a gate voltage to the metal/oxide/semiconductor (MOS) structure. In order to form the MOS structure, the oxide film with a thickness of $400 \mathrm{~nm}$ was grown on the Si substrate in $\mathrm{O}_{2} / \mathrm{H}_{2}$-gas at $1000^{\circ} \mathrm{C}$. Then, polycrystalline (poly-) Si with a thickness of $100 \mathrm{~nm}$ was prepared by a chemical vapor deposition at $640^{\circ} \mathrm{C}$ and phosphorus atoms were diffused into the poly-Si film at $875^{\circ} \mathrm{C}$ in order to form a metallic electrode. During the measurements, the $\mathrm{Si}$ substrate was grounded and a gate voltage, $V_{\mathrm{g}}$, was applied to the poly-Si film.

The annihilation characteristics of positrons in $\mathrm{SiO}_{2}$ films grown by an atmospheric-pressure chemical vapor deposition (APCVD) using tetraethylorthosilicate (TEOS, $\left.\mathrm{Si}\left(\mathrm{OC}_{2} \mathrm{H}_{5}\right)_{4}\right)$ and $\mathrm{O}_{3}$ were studied. The deposition apparatus of APCVD was described elsewhere [19]. The APCVD-SiO 2 films were prepared at different substrate temperatures and at different $\mathrm{O}_{3}$ concentrations. The $\mathrm{SiO}_{2}$ film grown by CVD using $\mathrm{SiH}_{4} / \mathrm{N}_{2} \mathrm{O}$ and that by wet oxidation were also studied. The growth conditions of those films are listed in Table I. The contents of $\mathrm{H}_{2} \mathrm{O}$ and bonding structures in the APCVD-SiO 2 films were analyzed by a moisture evolution analyzer and Fourier transform infrared spectroscopy (FTIR), respectively.

It is well known that impurities such as $\mathrm{H}_{2} \mathrm{O}$ or $-\mathrm{OH}$ bonds with high concentration exsist in CVD$\mathrm{SiO}_{2}$ films grown by using $\mathrm{TEOS} / \mathrm{O}_{3}$ [20]. The implantation of oxygen ions into Si substrates decreases the concentration of such impurities in $\mathrm{SiO}_{2}$ films. Separation by implanted oxygen (SIMOX) wafers were characterized in the present experiment. The implantation of $200 \mathrm{keV} \mathrm{O}^{+}$ions was performed at $550^{\circ} \mathrm{C}$ up to the dose of $1 \times 10^{18} \mathrm{O} / \mathrm{cm}^{2}$. After ion implantation, the specimen was subsequently annealed at $1325^{\circ} \mathrm{C}$ under $\mathrm{Ar}$ and $\mathrm{O}_{2}$ gas atmosphere for 8 hours. After this annealing treatment, the implantation was performed again with the same conditions. Finally the specimen was

Table I The growth conditions of the $\mathrm{SiO}_{2}$ films.

\begin{tabular}{|c|c|c|c|c|}
\hline specimen & $\begin{array}{c}\text { growth } \\
\text { condition }\end{array}$ & $\begin{array}{c}\text { substrate } \\
\text { temperature } \\
\left({ }^{\circ} \mathrm{C}\right)\end{array}$ & atmosphere & $\begin{array}{c}\text { film thickness } \\
\text { (nm) }\end{array}$ \\
\hline TEOS/O 3 No. 1 & $\overline{\mathrm{APCVD}}$ & 370 & TEOS/O3 (5.6\%) & 312 \\
\hline TEOS $/ \mathrm{O}_{3}$ No. 2 & APCVD & 400 & TEOS/O3 $(5.6 \%)$ & 322 \\
\hline TEOS $/ \mathrm{O}_{3}$ No. 3 & APCVD & 430 & TEOS/O3 $(5.6 \%)$ & 288 \\
\hline TEOS $/ \mathrm{O}_{3}$ No. 4 & APCVD & 400 & TEOS $/ \mathrm{O}_{3}(0.56 \%)$ & 305 \\
\hline $\mathrm{SiH}_{4} / \mathrm{N}_{2} \mathrm{O}$ & CVD & 800 & $\mathrm{SiH}_{4} / \mathrm{N}_{2} \mathrm{O}$ & 600 \\
\hline thermal Oxide & $\begin{array}{c}\text { thermal } \\
\text { oxidization }\end{array}$ & 1000 & $\mathrm{H}_{2} \mathrm{O} / \mathrm{O}_{2}$ & 506 \\
\hline
\end{tabular}

Table II Conditions of the SIMOX specimens after each annealing treatment.

\begin{tabular}{ccccc}
\hline \hline specimen & total dose $\left(\mathrm{O} / \mathrm{cm}^{2}\right)$ & $\begin{array}{c}\text { annealing } \\
\text { condition }\end{array}$ & $\begin{array}{c}\text { thickness of the } \\
\text { SOI layer }(\mathrm{nm})\end{array}$ & $\begin{array}{c}\text { thickness of the } \\
\mathrm{SiO}_{2} \text { film }(\mathrm{nm})\end{array}$ \\
\hline $\begin{array}{c}\text { after first } \\
\text { implantation } \\
\text { after first }\end{array}$ & $1 \times 10^{18}$ & - & - & - \\
$\begin{array}{c}\text { annealing } \\
\text { after second } \\
\text { implantation } \\
\text { after second } \\
\text { annealing }\end{array}$ & $1 \times 10^{18}$ & $\begin{array}{c}1325^{\circ} \mathrm{C}, \mathrm{Ar}+\mathrm{O}_{2}, \\
8 \text { hours }\end{array}$ & 280 & 330 \\
\hline \hline
\end{tabular}


annealed again. Thus, the total implantation dosage was $2 \times 10^{18} \mathrm{O} / \mathrm{cm}^{2}$. The conditions of the specimens after each annealing treatment are listed in Table II, where the thickness of the silicon on insulator (SOI) layer and that of the $\mathrm{SiO}_{2}$ layer were measured using a cross-sectional transmission electron microscope.

The monoenergetic positron beam line at the University of Tsukuba was used for measurements of Doppler broadening profiles [21]. Positrons emitted from a $22 \mathrm{Na}$ source were moderated by wellannealed tungsten foils. The slow positrons obtained were guided by a magnetic field through multiple discrete acceleration lenses and struck the specimen with an adjusted energy between $0 \mathrm{keV}$ and $30 \mathrm{keV}$. Doppler broadening profiles of the annihilation radiation were measured with a Ge detector as a function of incident positron energy, $E$. The annihilation spectrum was characterized by the $S$ parameter.

The observed $S-E$ relations for the $\mathrm{SiO}_{2} / \mathrm{Si}$ specimens were analyzed by a computer code "VEPFIT" developed by van Veen $e t$ al. [22]. The one-dimensional diffusion model of positrons is described by [2];

$$
D_{+} \frac{\mathrm{d}^{2}}{\mathrm{dz}^{2}} n(z)-\frac{\mathrm{d}}{\mathrm{dz}}[v(z) n(z)]-\kappa_{\mathrm{eff}}(z) n(z)+P(z, E)=0,
$$

where $D_{+}$is the diffusion coefficient of positrons, $n(z)$ is the probability density of positrons at a distance $z$ from the surface, $v(z)$ is the drift velocity, $\kappa_{\text {eff }}(z)$ is the effective decay rate of positrons, and $P(z, E)$ is the implantation profile of positrons. $v(z)$ is connected to the mobility of positrons, $\mu$, and the electric field, $E(z)$ by the relation; $v(z)=\mu E(z)$. In VEPFIT, $P(z, E)$ is described by the expression;

$$
P(z, E)=\frac{m z^{m-1}}{z_{0}^{m}} \exp \left[-\left(\frac{z}{z_{0}}\right)^{m}\right]
$$

where $m$ is the shape parameter of $P(z, E) . \quad z_{0}$ is proportional to the mean implantation depth of positrons, $\bar{z}$, as follows; $z_{0}=\bar{z} / \Gamma[(1 / m)+1]$, where $\Gamma$ is the gamma function. $\bar{z}$ has a power-law dependence on the incident positron energy, $\bar{z}=A E^{\mathrm{n}}$, where $A$ is a constant depending on the density of the target, $\rho,(A=C / \rho, C$ is a constant $)$ and $n$ is an energy- and material-dependent constant. In this article, the values of $m, n$ and $C$ were fixed as $2,1.6$ and $3.32 \mu \mathrm{gcm}^{-2} \mathrm{keV}^{-1.6}$ [11], respectively. The observed $S-E$ plots for the $\mathrm{SiO}_{2} / \mathrm{Si}$ specimens were fitted by the relation,

$$
S(E)=S_{\mathrm{S}} F_{\mathrm{S}}(E)+S_{\mathrm{0}} F_{\mathrm{o}}(E)+S_{\mathrm{i}} F_{\mathrm{i}}(E)+S_{\mathrm{Si}} F_{\mathrm{Si}}(E),
$$

where $S_{\mathrm{S}}, S_{\mathrm{O}}, S_{\mathrm{i}}$ and $S_{\mathrm{Si}}$ are the characteristic values of the $S$ parameter for the annihilation of positrons at the surface, in the $\mathrm{SiO}_{2}$ film, at the $\mathrm{SiO}_{2} / \mathrm{Si}$ interface and in the $\mathrm{Si}$ substrate, respectively. $F(E)$ is the fraction of positrons annihilating in each region $\left(\Sigma F_{\mathrm{i}}(E)=1\right)$.

A pulsed monoenergetic positron beam line constructed at Electrotechnical Laboratory was used in order to measure lifetime spectra of positrons. The detail of the system was described elsewhere [23]. The lifetime spectra were obtained by measuring the time interval between the timing signal derived electrically from the pulsing system and the annihilation $\gamma$ ray detected by $\mathrm{BaF}_{2}$ scintillation detector. Total counts of about $2 \times 10^{5}$ were accumulated for each lifetime spectrum.

The lifetime spectrum of positrons, $I(t)$, is expressed by,

$$
I(t)=\sum I_{\mathrm{i}} \exp \left(-t / \tau_{\mathrm{i}}\right)
$$

where $\tau_{\mathrm{i}}$ and $I_{\mathrm{i}}$ are the lifetime of the $\mathrm{i}$-th component and its intensity $\left(\Sigma I_{\mathrm{i}}=1\right)$, respectively. The observed lifetime spectra in the present experiment were analyzed by RESOLUTION [24] with the time resolution of $\sim 280 \mathrm{ps}$.

\section{RESULTS AND DISCUSSION}

Figure 1 shows the $S$ parameter as a function of incident positron energy, $E$, for the $S_{i O}(166 \mathrm{~nm}) / \mathrm{Si}$ specimens fabricated by thermal oxidation. The mean implantation depth of positrons is shown below the horizontal axis in the figure, together with $E$. At high $E(\sim 20 \mathrm{keV})$, the value of the $S$ parameter was 
found to approach a constant value. This indicates that almost all positrons are implanted into bulk $\mathrm{Si}$ in this energy range. At $E=4 \mathrm{keV}$, dips in the $S-E$ plots were observed. Since this energy corresponds to the depth of the $\mathrm{SiO}_{2} / \mathrm{Si}$ interface, the observed decrease in the value of $S$ can be associated with the annihilation of positrons at the $\mathrm{SiO}_{2} / \mathrm{Si}$ interface. In the region between $2 \mathrm{keV}$ and $3 \mathrm{keV}$, the value of $S$ was larger than that at $E=4 \mathrm{keV}$. This is due to the annihilation of positrons in the $\mathrm{SiO}_{2}$ film. For the $\mathrm{SiO}_{2} / \mathrm{Si}$ specimen fabricated at $1000^{\circ} \mathrm{C}$, the value of $S$ in this energy range was found to be larger than that for the specimen fabricated at $650^{\circ} \mathrm{C}$. At $E \cong 0 \mathrm{keV}$, the lowest value of $S$ was observed. This is associated with the annihilation of positrons at the surface of the specimen.

The observed $S-E$ plots were analyzed by VEPFIT. The diffusion length of positrons in electricfield-free $\mathrm{Si}, L_{\mathrm{d}(\mathrm{Si})}$, and the value of $S_{\mathrm{Si}}$ were fixed at $200 \mathrm{~nm}$ [25] and 0.5343 , respectively. According to the analysis of $S-E$ plots for $\mathrm{SiO}_{2} / \mathrm{Si}$ specimens by Au et al. [12], the thickness of the interface layer and the diffusion length of positrons in this layer were fixed at $2 \mathrm{~nm}$ and $0.01 \mathrm{~nm}$, respectively. It was found that both $S-E$ plots can be fitted by using $S_{\mathrm{i}}=0.49$ and $E_{\mathrm{Si}}=5 \times 10^{3} \mathrm{~V} / \mathrm{cm}$, where $E_{\mathrm{Si}}$ is the electric field in the Si substrate. The value of $E_{\mathrm{Si}}$ was found to strongly depend on the shape parameters of the implantation profile of positrons and the value of $S_{\mathrm{i}}$. The results of the fitting are shown as solid curves in Fig. 1.

The derived values of $S_{0}$ were 0.524 and 0.526 , and those of the diffusion length of positrons in the $\mathrm{SiO}_{2}$ film, $L_{\mathrm{d}(\mathrm{o})}$, were $9.7 \mathrm{~nm}$ and $8.9 \mathrm{~nm}$, for the specimens fabricated at $650^{\circ} \mathrm{C}$ and at $1000^{\circ} \mathrm{C}$, respectively. Nielsen et al. [4] already reported that the value of the $S$ parameter drastically decreased at the $\mathrm{SiO}_{2} / \mathrm{Si}$ interface. Lynn et al. [6] found that the annihilation characteristics of positrons at the $\mathrm{SiO}_{2} / \mathrm{Si}$ interface were very sensitive to hydrogen exposure. They suggested that the decrease of $S$ at the $\mathrm{SiO}_{2} / \mathrm{Si}$ interface can be attributed to the strong interaction between positrons and the hydrogen modified interface. The small value of $S_{\mathbf{i}}(0.49)$ derived in the present experiment also can be attributed to such phenomena.

Figures 2 and 3 show the lifetimes and the second intensity for the $\mathrm{SiO}_{2}(166 \mathrm{~nm}) / \mathrm{Si}$ specimens as a function of incident positron energy, where the observed lifetime spectra were decomposed into two components. In Fig. 2 , the value of $\tau_{2}$ was found to be shorter than the intrinsic lifetime of o-Ps $(\sim 140$ ns). However, this value is longer than the typical lifetime of positrons in crystalline solids [17]. Therefore, this annihilation mode can be associated with the pick-off annihilation of o-Ps. The presence of o-Ps should be associated with that of $\mathrm{p}$-Ps, too. Thus, the formation probability of Ps in

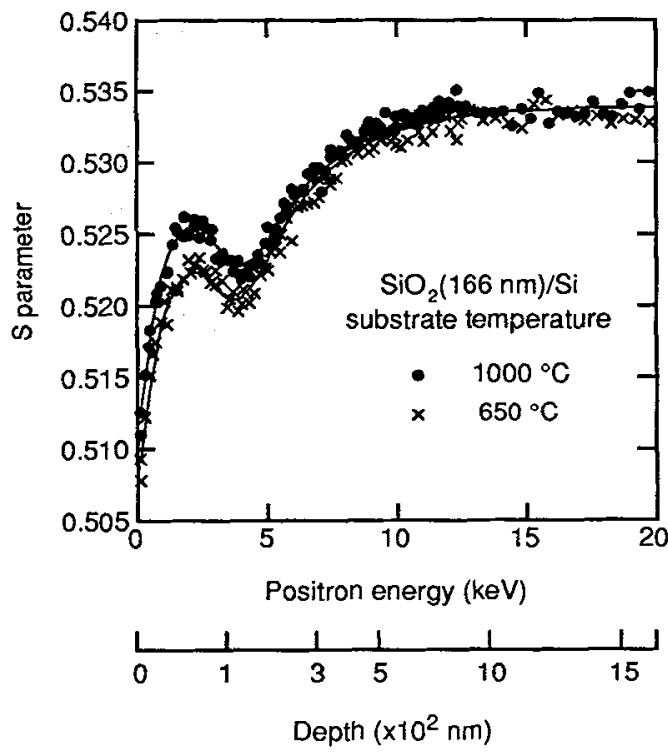

Fig. 1 The Doppler-broadened lineshape parameter $S$ as a function of incident positron energy for the $\mathrm{SiO}_{2}(166 \mathrm{~nm}) / \mathrm{Si}$ specimens. These $\mathrm{SiO}_{2}$ films were grown by thermal oxidation at $1000^{\circ} \mathrm{C}$ and $650^{\circ} \mathrm{C}$, respectively. the $\mathrm{SiO}_{2}$ films can be estimated as about $90 \%$ $\left(I_{3}+I_{3} / 3\right)$. Dannefaer et al. [26] reported that the lifetime spectrum for a single crystal quartz ( $\alpha$ $\mathrm{SiO}_{2}$ ) can be decomposed into three components. They reported that the longest lifetime was $1.4 \mathrm{~ns}$ with the intensity of $1.5 \%$. This component can be associated with the pick-off annihilation of oPs. For the $\mathrm{SiO}_{2}$ films, the intensity corresponding to the annihilation of Ps was about $90 \%$, while that in $\alpha-\mathrm{SiO}_{2}(\sim 2 \%)$ is far less than this value. Because of the high sensitivity of positrons for vacancy-type defects, almost all positrons are considered to be trapped by open atomic spaces in amorphous materials. If a specimen contains a large number of open-spaces such as microvoids or pores, positrons can form Ps in such regions under some conditions. Amorphous $\mathrm{SiO}_{2}$ specimens have been considered to contain such open-space defects. Thus, the formation of $\mathrm{Ps}$ in the $\mathrm{SiO}_{2}$ films is considered to be enhanced by the trapping of positrons in openspace defects. Uedono and Tanigawa [27] investigated the annihilation characteristics of Ps in $\mathrm{v}-\mathrm{SiO}_{2}$ specimens by measurements of twodimensional angular correlation annihilation radiation. From the measurements, it was found that $\mathrm{Ps}$ formed in the $\mathrm{v}-\mathrm{SiO}_{2}$ specimens annihilates with broadened momentum distribution. This fact was attributed to the 


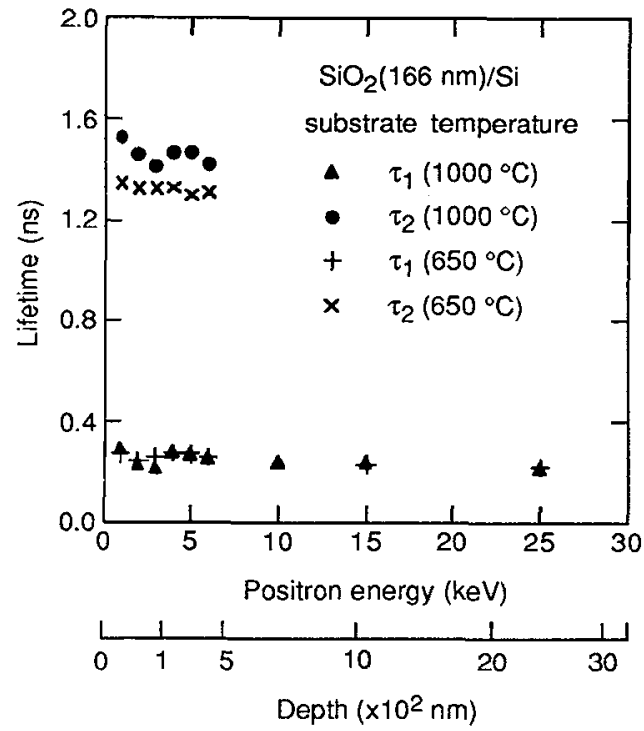

Fig. 2 The lifetimes as a function of incident positron energy for the $\mathrm{SiO}_{2}(166 \mathrm{~nm}) / \mathrm{Si}$ specimens.

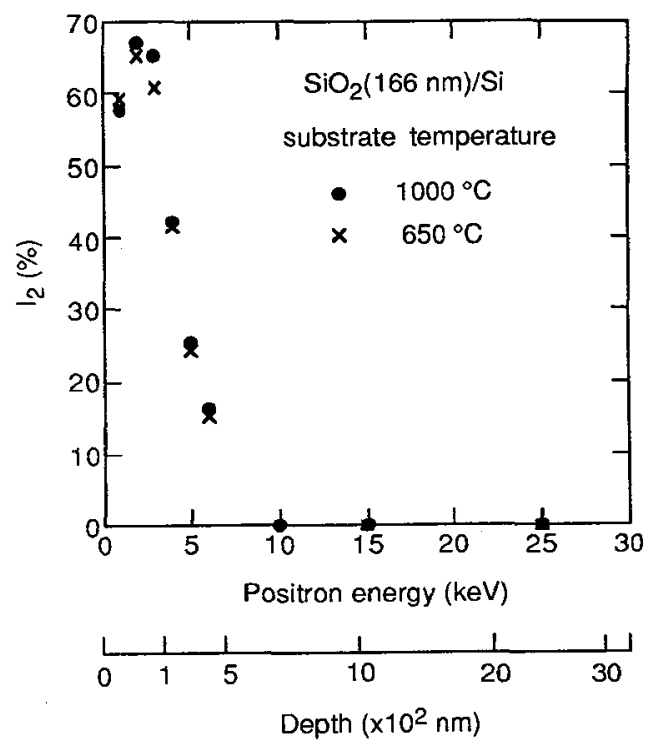

Fig. 3 The second intensity, $I_{2}$, as a function of incident positron energy for the $\mathrm{SiO}_{2}(166$ $\mathrm{nm}) / \mathrm{Si}$ specimens.

momentum uncertainty due to the localization of Ps in a finite dimension of open-space defects. Therefore, it can be concluded that almost all Ps formed in amorphous $\mathrm{SiO}_{2}$ specimens is trapped by open-space defects. For the $\mathrm{SiO}_{2} / \mathrm{Si}$ specimen fabricated at $650^{\circ} \mathrm{C}$, the value of $\tau_{2}$ at $E=2 \mathrm{keV}$ was found to be smaller than that for the specimen at $1000^{\circ} \mathrm{C}$ (Fig. 2). This result suggests that the mean size of open-space defects in the $\mathrm{SiO}_{2}$ film grown with low substrate temperature is smaller than that in the $\mathrm{SiO}_{2}$ film grown with high substrate temperature. Therefore, it can be concluded that the size of open-space defects decreases with decreasing the growth rate of the $\mathrm{SiO}_{2}$ film. The slow growth rate is considered to cause a dense network in the $\mathrm{SiO}_{2}$ film.

In order to know the annihilation characteristics of positrons at the $\mathrm{SiO}_{2} / \mathrm{Si}$ interface in more detail, the positron lifetime spectra were measured as a function of the gate voltage for the MOS specimen. The observed lifetime spectra were decomposed into two components. Figures 4 and 5 show the gate voltage dependence of the lifetime and that of the second intensity at $E=5.5 \mathrm{keV}$. At this incident positron energy, $\bar{z}$ coincides with the region of the $\mathrm{SiO}_{2}$ film. From Figs. 4 and 5, it was found that the value of $I_{2}$ decreased with increasing gate voltage, although no drastic change in the value of $\tau_{2}$ was observed. In the inversion sate of the MOS specimen, positrons implanted into the $\mathrm{SiO}_{2}$ film diffuse towards the $\mathrm{SiO}_{2} / \mathrm{Si}$ interface by the electric field. Thus, the observed decrease in the value of $I_{2}$ can be attributed to the enhanced diffusion of positrons towards the $\mathrm{SiO}_{2} / \mathrm{Si}$ interface. This decrease of $I_{2}$ can be attributed to an accumulation of positrons at the $\mathrm{SiO}_{2} / \mathrm{Si}$ interface and the resultant inhibition of the $\mathrm{Ps}$ formation. Since the annihilation from the p-Ps state produces $\gamma$ rays with very sharp energy width, the annihilation of p-Ps increases the value of the $S$ parameter. Therefore, the observed decrease in the value of $S$ parameter at the $\mathrm{SiO}_{2} / \mathrm{Si}$ interface (Fig. 1) can be attributed to the inhibition of the Ps formation.

Figures 6 and 7 show the lifetimes of positrons and the second intensities for the $\mathrm{SiO}_{2}$ films fabricated by CVD and by wet oxidation, respectively. From Fig. 7, it can be seen that the value of $I_{2}$ for the APCVD-SiO 2 films grown by using TEOS/O 3 was smaller than that for the thermal oxide film. This means that the formation probability of Ps decreased in the APCVD-SiO 2 specimens. It can be concluded that the formation probability of Ps increased with increasing the substrate temperature and it decreased with decreasing the concentration of $\mathrm{O}_{3}$. From the measurements of FTIR, it was found that the concentration of $-\mathrm{OH}$ bonds decreased with increasing the substrate temperature. By using a moisture evolution analyzer, the content of $\mathrm{H}_{2} \mathrm{O}$ for the APCVD-SiO 2 film grown at $0.5 \% \mathrm{O}_{3}$ was 


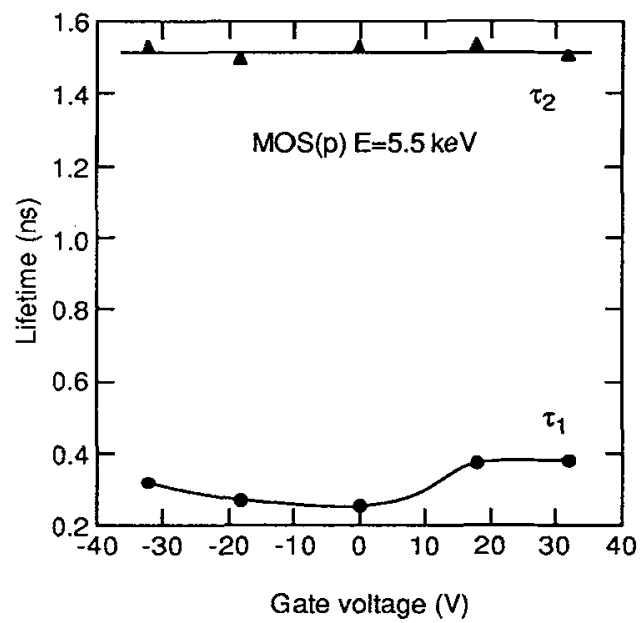

Fig. 4 The gate voltage dependence of the lifetime at $E=5.5 \mathrm{keV}$. The lifetime spectra were decomposed into two components, where the long-lived component was attributed to the pick-off annihilation of o-Ps.

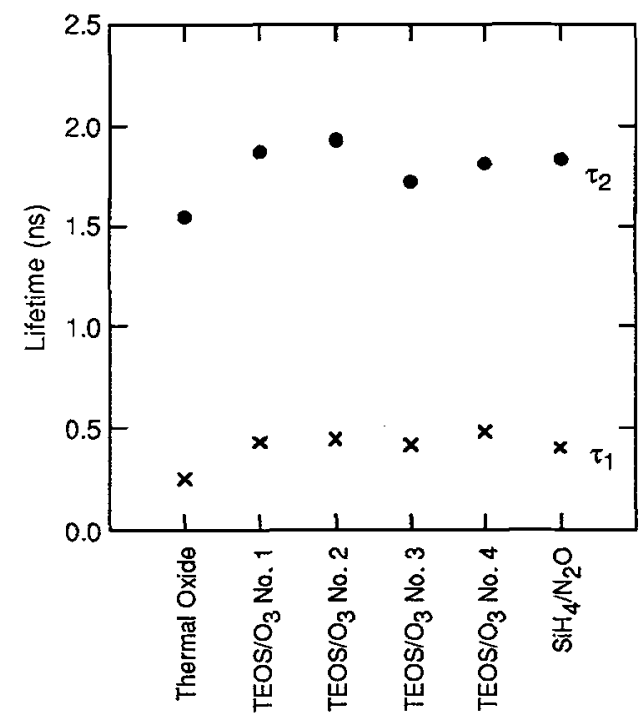

Fig. 6 The lifetimes of positrons for the $\mathrm{SiO}_{2}$ films fabricated by CVD and by wet oxidation.

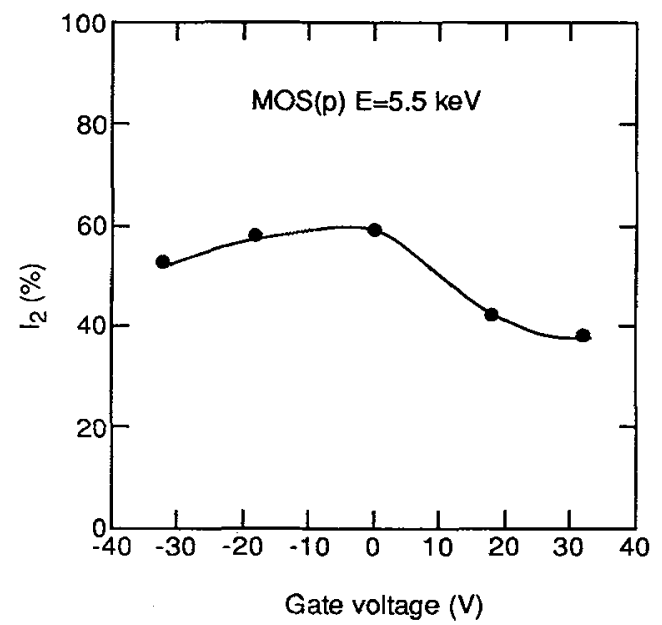

Fig. 5 The gate voltage dependence of the intensity corresponding to the pick-off annihilation of o-Ps at $E=5.5 \mathrm{keV}$.

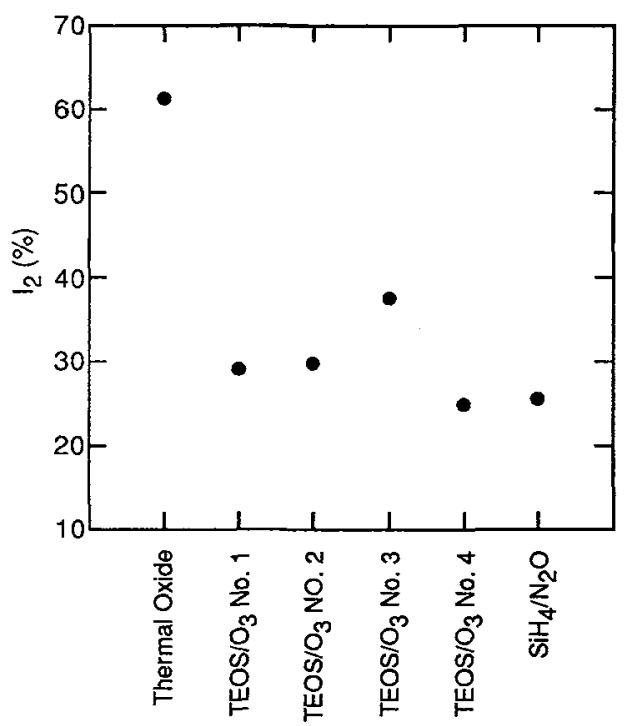

Fig. 7 The second intensities for the $\mathrm{SiO}_{2}$ films fabricated by CVD and by wet oxidation.

obtained as $4.3 \mathrm{wt} \%$ and that for the film grown at $5 \% \mathrm{O} 3$ was $2.2 \mathrm{wt} \%$, where the substrate temperature was $400^{\circ} \mathrm{C}$. This fact suggests that the concentration of $-\mathrm{OH}$ bonds in the APCVD-SiO 2 film decreases with increasing the concentration of $\mathrm{O}_{3}$. Since the formation of Ps needs larger open spaces or a lower electron density than the volume or electron density around point defects, the trapping of positrons by point defects such as. oxygen vacancies is considered to suppress the formation of Ps. Uedono $e t$ al. [28] found that the formation probability of $\mathrm{Ps}$ in $\mathrm{v}-\mathrm{SiO}_{2}$ was decreased by the trapping of positrons into 
vacancy-type defects introduced by electron irradiation. However, for the APCVD-SiO 2 films grown by using TEOS/O 3 , the concentration of point defects is considered to be low, because of the high concentration of $\mathrm{H}_{2} \mathrm{O}$ and a resultant formation of Si-OH bonds. Thus, the concentration of the point defects in the thermal oxide film or in the CVD-SiO 2 film grown by using $\mathrm{SiH}_{4} / \mathrm{N}_{2} \mathrm{O}$ is considered to be higher than that for the APCVD-SiO ${ }_{2}$ films grown by using $\mathrm{TEOS} / \mathrm{O}_{3}$. Therefore, the inhibition of the Ps formation can be attributed to the interaction between positrons and -OH bonds in $\mathrm{SiO}_{2}$ films. For the $\mathrm{SiO}_{2}$ films with the high concentration of $-\mathrm{OH}$ bonds, positrons are considered to be trapped by $-\mathrm{OH}$ bonds and annihilate before the formation of Ps.

The inhibition of the Ps formation by the trapping of positrons into vacancy-type defects was observed for the SIMOX specimens [29]. Figures 8 and 9 show the lifetimes of positrons and the second intensities for the $200-\mathrm{keV} \mathrm{O}^{+}$-ion implanted $\mathrm{Si}$ specimens, respectively. In Fig. 9, it can be seen that the value of $I_{2}$ was increased by the first annealing treatment. Although the value of $I_{2}$ decreased after the second ion implantation, the highest value of $I_{2}$ was observed after the final annealing treatment. However, no drastic change in the value of $\tau_{2}$ was observed for the specimens after each annealing treatment (Fig. 8). The changes in the value of $I_{2}$ are due to the formation of the $\mathrm{SiO}_{2}$ layer upon annealing treatment. For the annealed specimen with a dose of $2 \times 10^{18} \mathrm{O} / \mathrm{cm}^{2}$, the highest value of $I_{2}$ was observed. However, the specimen with a dose of $2 \times 10^{18} \mathrm{O} / \mathrm{cm}^{2}$ before the annealing treatment, the value of $I_{2}$ was smaller than that for the annealed one. This fact can be attributed to the trapping of positrons by vacancy-type defects introduced by $\mathrm{O}^{+}$-ion implantation, and the resultant inhibition of the Ps formation. For the annealed specimen with a dose of $1 \times 10^{18} \mathrm{O} / \mathrm{cm}^{2}$, the value of $I_{2}$ was smaller than that for the one with a dose of $2 \times 10^{18} \mathrm{O} / \mathrm{cm}^{2}$. For the annealed specimen after the implantation of $\mathrm{O}^{+}$-ions with a dose of $1 \times 10^{18} \mathrm{O} / \mathrm{cm}^{2}$, because of a lack of oxygen atoms, oxygen vacancies with high concentration are considered to exist in the $\mathrm{SiO}_{2}$ film. Thus, the observed small value of $I_{2}$ was also attributed to the inhibition of the Ps formation by the trapping of positrons by vacancy-type defects.

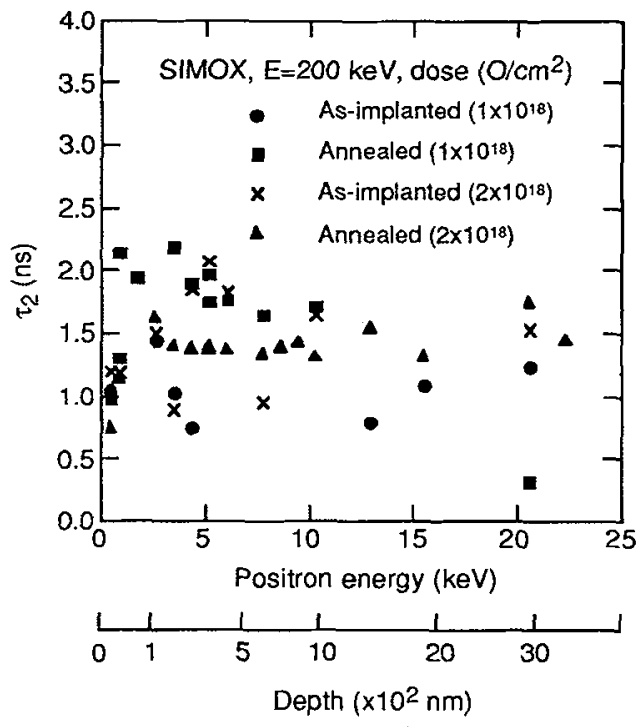

Fig. 8 The second lifetime $\tau_{2}$ as a function of incident positron energy for the $200-\mathrm{keV} \mathrm{O}^{+}-$ ion implanted specimens as-implanted and after annealing.

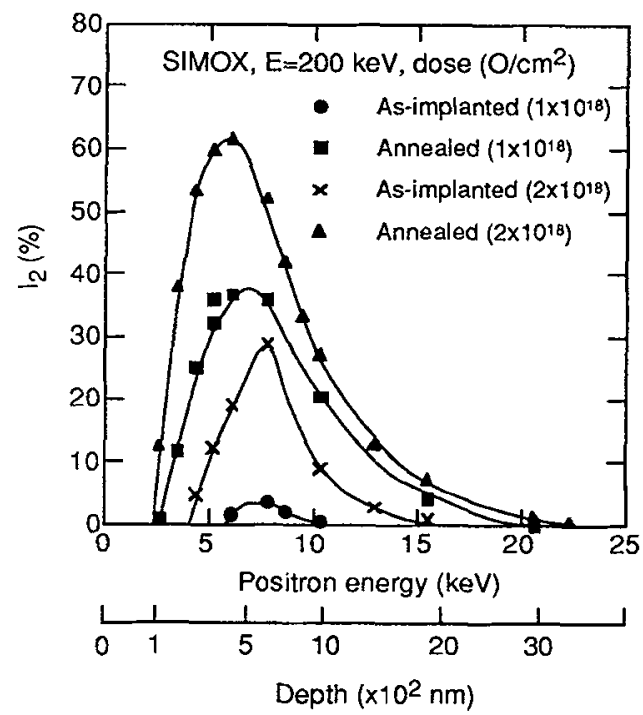

Fig. 9 The second component $I_{2}$ as a function of incident positron energy for the $200-\mathrm{keV} \mathrm{O}^{+}$ion implanted specimens as-implanted and after annealing.

\section{CONCLUSION}

We have studied the annihilation characteristics of positrons in $\mathrm{SiO}_{2} / \mathrm{Si}$ specimens fabricated by various oxidation techniques. In the $\mathrm{SiO}_{2}$ film, about $90 \%$ of positrons were found to annihilate from the Ps states. This fact was due to the trapping of positrons by open-space defects and the resultant enhanced formation of $\mathrm{PS}$ in such regions. For the $\mathrm{SiO}_{2} / \mathrm{Si}$ specimen fabricated at $650^{\circ} \mathrm{C}$, the value of 
$\tau_{2}$ at $E=2 \mathrm{keV}$ was found to be smaller than that for the specimen at $1000^{\circ} \mathrm{C}$. This result suggests that the mean size of open-space defects in the $\mathrm{SiO}_{2}$ film grown with low substrate temperature is smaller than that in the $\mathrm{SiO}_{2}$ film grown with high substrate temperature. In the $\mathrm{CVD}-\mathrm{SiO}_{2}$ films, the formation probability of Ps was found to be lower than that in the $\mathrm{SiO}_{2}$ film grown by wet oxidation. The formation probability of Ps decreased with increasing the concentration of -OH bonds in the APCVD$\mathrm{SiO}_{2}$ films grown by using $\mathrm{TEOS} / \mathrm{O}_{3}$. These facts can be attributed to the interaction between positrons and $-\mathrm{OH}$ bonds. For the SIMOX specimens, the intensity of o-Ps was found to be sensitive to the formation of the $\mathrm{SiO}_{2}$ layer upon the annealing treatment. The present investigation shows that positrons provide a sensitive and nondestructive probe for the characterization of $\mathrm{SiO}_{2}$ films grown on $\mathrm{Si}$ substrates.

\section{References}

[1] L.E. Katz, VLSI Technology, (McGraw-Hill, New York, 1988) pp. 98-140.

[2] Schultz P.J. and Lynn K.G., Rev. Mod. Phys. 60 (1988) 701-779.

[3] Chen Y.C., Lynn K.G. and Nielsen B., Phys. Rev. B 37 (1988) 3105-3108.

[4] Nielsen B., Lynn K.G., Welch D.O., Leung T.C. and Rubloff G.W., Phys, Rev. B 40 (1989) 14341437.

[5] Lynn K.G., Nielsen B. and Welch D.O., Can. J. Phys. 67 (1989) 818-820.

[6] Rubloff G.W., Nielsen B., Lynn K.G., Welch D.O. and Leung T.C., Vacuum 41 (1990) 790-792.

[7] Kong Y., Leung T.C., Asoka-Kumar P., Nielsen B. and Lynn K.G., J. Appl. Phys. 70 (1991) 2874 -2879 .

[8] Uedono A., Wei L., Tabuki Y., Kondo H., Tanigawa S. and Ohji Y., Mater. Sci. Forum 105-110 (1992) 1475-1478.

[9] Asoka-Kumar P., Leung T.C., Lynn K.G., Nielsen B., Forcier M.P., Weinberg M.P. and Rubloff G.W., J. Appl. Phys. 71 (1992) 5606-5609.

[10] Ohji Y., Uedono A., Wei L., Tabuki Y. and Tanigawa S., Mat. Res. Soc. Symp. Proc. 262 (1992) 313-318.

[11] Leung T.C., Asoka-Kumar P., Nielsen B. and Lynn K.G., J. Appl. Phys. 73 (1993) 168-184.

[12] Au H.L., Asoka-Kumar P., Nielsen B. and Lynn K.G., J. Appl. Phys. 73 (1993) 2972-2976.

[13] Fujinami M. and Chilton N.B., Appl. Phys. Lett. 62 (1993) 1131-1133.

[14] Khatri R., Asoka-Kumar P., Nielsen B., Roeling L.O. and Lynn K.G., Appl. Phys. Lett. 63 (1993) 385-387.

[15] Uedono A., Wei L., Tanigawa S., Suzuki R., Ohgaki H., Mikado T. and Ohji Y., J. Appl. Phys. 74 (1993) 7251-7256.

[16] Uedono A., Wei L., Tanigawa S., Suzuki R., Ohgaki H., Mikado T. and Fujino K., J. Appl. Phys. 75 (1994) 216-222.

[17] Hautojärvi P. and Vehanen A, Positrons in Solids (Springer-Verlag, Berlin, 1979) pp. 1-23.

[18] Schrader D.M. and Jean Y.C., Positron and Positronium Chemistry (World Scientific, Singapore, 1990) p. 1-26.

[19] Fujino K., Nishimoto Y., Tokumasu N. and Maeda N., J. Electrochem. Soc. 137 (1990) 2883-2887.

[20] Nguyen S., Dobuzinsky D., Harmon D., Gleason R. and Fridmann S., J. Electrochem. Soc. 137 (1990) 2209-2215.

[21] Uedono A., Wei L., Dosho C., Kondo H., Tanigawa S. and Tamura M., Jpn. J. Appl. Phys. 30 (1991) 1597-1603.

[22] Van Veen A., Schut H., de Vries J., Hakvoort R.A. and Ijpma M.R., Positron Beams for Solids and Surfaces, AIP Conf. Proc. 218, (AIP, New York, 1990) p. 171-196.

[23] Suzuki R., Kobayashi Y., Mikado T., Ohgaki H., Chiwaki M., Yamazaki T. and Tomimasu T., Jpn. J. Appl. Phys. 30 (1991) L532-L534.

[24] Kirkegaard P., Eldrup M., Mogensen O.E. and Pedersen N.J., Comput. Phys. Commun. 23 (1981) 307-335.

[25] Nielsen B., Lynn K.G., Vehanen A. and Schultz P.J., Phys. Rev. B 32 (1985) 2296-2301.

[26] Dannefaer S., Bretagnon T. and Kerr D., J. Appl. Phys. 74 (1993) 884-890.

[27] Uedono A. and Tanigawa S., Jpn. J. Appl. Phys. 32 (1993) 2687-2691.

[28] Uedono A., Watauchi S., Ujihira Y. and Yoda O., Hyperfine Interactions in press.

[29] Uedono A., Wei L., Tanigawa S., Suzuki R., Ohgaki H., Mikado T., Kametani H., Akiyama H., Yamaguchi Y. and Koumaru M., Jpn. J. Appl. Phys. 32 (1993) 3682-3686. 